\title{
Sporothrix brasiliensis induces a more severe disease associated with sustained Th17 and regulatory T cells responses than Sporothrix schenckii sensu stricto in mice
}

\author{
Alexander Batista-Duharte ${ }^{\text {a, }}$, Damiana Téllez-Martínez ${ }^{\text {a }}$, \\ Cleverton Roberto de Andrade ${ }^{\mathrm{b}}$, Deivys Leandro Portuondo ${ }^{\mathrm{a}}$, \\ Juliana Aparecida Jellmayer ${ }^{a}$, Marisa Campos Polesi ${ }^{\mathrm{a}}$, Iracilda Zeppone Carlos ${ }^{\mathrm{a}, * *}$ \\ a São Paulo State University (UNESP), School of Pharmaceutical Sciences, Department of Clinical Analysis, Araraquara, SP, Brazil \\ b São Paulo State University (UNESP), School of Dentistry, Department of Physiology \& Pathology, Araraquara, SP, Brazil
}

\section{A R T I C L E I N F O}

\section{Article history:}

Received 7 April 2018

Received in revised form

30 July 2018

Accepted 17 August 2018

Available online 24 August 2018

Corresponding Editor: Julian Rutherford

\section{Keywords:}

Cytokines

Sporotrichosis

$\mathrm{T}$ helper cells

Tregs

Virulence

\begin{abstract}
A B S T R A C T
Little is known about the differences in the CD4+ T-cell response induced by Sporothrix schenckii and Sporothrix brasiliensis, the most virulent species that cause sporotrichosis. Here, the helper (Th) and regulatory T cells (Tregs) responses were evaluated comparatively in a murine model of sporotrichosis on days 7, 21 and 35 after subcutaneous infection with either S. schenckii or S. brasiliensis conidia. The fungal load was measured at the site of infection, as well as in the liver and spleen. The Th1/Th17/Tregs responses were analyzed in the spleen, while the level of IL-2, IL-4, IL-6, TNF-alpha, IFN-y, IL-17A and IL-10 cytokines were measured at the local site of infection on $24 \mathrm{~h}$ postinfections and in sera on the indicated days. S. brasiliensis caused a longer-lasting infection in the skin and chronic systemic dissemination associated to more severe granulomatous lesions. Similar Th1/Th1-Th17/Tregs responses were induced by both S. brasiliensis and S. schenckii on 7th and 21st d.p.i but on 35 d.p.i a reduction of Th1 and Th1Th17 cells, associated to higher values of Th17/Tregs cells was observed only in S. brasiliensis-infected mice. In summary, S. brasiliensis caused a more severe disease associated with sustained Th17/Tregs responses than S. schenckii in mice.
\end{abstract}

๑) 2018 British Mycological Society. Published by Elsevier Ltd. All rights reserved.

\section{Introduction}

Sporotrichosis is the most reported and globally distributed subcutaneous mycosis (Bonifaz and Tirado-Sánchez, 2017). Although considered endemic in tropical and subtropical countries, sporotrichosis has been increasingly observed in other regions and currently is regarded as an important and emergent disease. The exact prevalence of sporotrichosis is unknown due to its lack of reportable disease status. However, the disease has been reported

\footnotetext{
* Corresponding author. Laboratório de Imunología Clínica, Dpto Analises Clinicas, Faculdade de Ciências Farmacêuticas, Universidade Estadual Paulista (UNESP) Rod, Araraquara-Jaú - Km 1, Campus Ville, CEP, 14800-903, Araraquara, São Paulo, Brazil.

** Corresponding author. Laboratório de Imunología Clínica, Dpto Analises Clinicas, Faculdade de Ciências Farmacêuticas, Universidade Estadual Paulista (UNESP) Rod, Araraquara-Jaú - Km 1, Campus Ville, CEP, 14800-903, Araraquara, São Paulo, Brazil.

E-mail addresses: batistaduhartea@gmail.com (A. Batista-Duharte), carlosiz@ fcfar.unesp.br (I.Z. Carlos).
}

in a wide range of countries, including the United States, South America (Brazil, Colombia, Guatemala, Mexico, Peru), South Africa, Asia (China, India, Japan), and Australia (Chakrabarti et al., 2015; Carlos and Batista-Duharte, 2015). After a pioneer study that was conducted by Beurmann and Gougerot involving 250 cases of cutaneous sporotrichosis in France (Beurmann and Gougerot, 1912), the number of cases has decreased drastically in Europe, and currently, only sporadic cases have been recently reported in some countries such as Spain, Italy and Portugal (Carlos and BatistaDuharte, 2015). Sporothrix schenckii sensu lato, the etiologic agent of sporotrichosis, is a complex of at least four pathogenic species that include Sporothrix brasiliensis, S. schenckii sensu stricto, Sporothrix globosa, and Sporothrix luriei (de Beer et al., 2016). However, the two most important pathogenic species are both S. schenckii sensu stricto, which is responsible for human sporotrichosis worldwide and $S$. brasiliensis, which is the more virulent specie, involved in an expanding zoonosis transmitted by cats in Brazil (Arrillaga-Moncrieff et al., 2009; Castro et al., 2013; Della Terra et al., 2017). 
These fungi are common saprophyte of soil, decaying wood, hay, and sphagnum moss. Human or animal infection generally occurs by traumatic inoculation of soil, plants, and organic matter or through scratches or bites from animals (mostly cats) contaminated with the fungus, and more rarely by inhalation. Evidences suggests that $S$. schenckii sensu lato is able to modify its virulence under different environmental conditions (Téllez et al., 2014; BatistaDuharte et al., 2015). After inoculation, several mechanisms of the innate immunity are activated to control the infection directly and by stimulating the specific immune response (Carlos et al., 1994; Gonçalves et al., 2015; Ferreira et al., 2015; Maia et al., 2016; Jellmayer et al., 2017). The importance of these immune mechanisms for the control of S. schenckii-infection is evidenced by the higher fungal colonization and dissemination in immunosuppressed mouse models (Manente et al., 2018; Batista-Duharte et al., 2018a) and immunocompromised patients, mainly individuals with HIV-AIDS (Moreira et al., 2015).

It has long been appreciated that protective immunity against fungal pathogens is dependent on the activation of cellular adaptive immune responses involving Th1 and Th17 subsets of T lymphocytes while an elevated Th2 response promote fungal infections (van de Veerdonk and Netea, 2010). More debate exists about the role of regulatory $\mathrm{T}$ cells (Tregs), a subset of $\mathrm{T}$ cells with a $\mathrm{CD} 3+\mathrm{CD} 4+\mathrm{CD} 25+$ Foxp3+ phenotype, that regulate the immune responses. Some studies have shown that Tregs increase protective immunity against different fungi such as Candida albicans (Pandiyan et al., 2011; Netea et al., 2004) and Cryptococcus neoformans (Schulze et al., 2014; Wiesner et al., 2016), while in other models, Tregs promoted fungal infection (Felonato et al., 2012; Whibley et al., 2014).

Recently, it was reported that differences in the cell wall composition between S. schenckii sensu stricto and S. brasiliensis influence the contribution of immune receptors during cytokine stimulation by human mononuclear cells (Martínez-Álvarez et al., 2017). Other recent studies showed that several proteins potentially involved in immune evasion strategies are expressed in $S$. brasiliensis but not in S. schenckii (Rossato et al., 2018), and that $S$. brasiliensis produces the highest levels of oxidative stress in a murine model among the species of $S$. schenckii sensu lato (Mario et al., 2017). These findings suggest that there must also be differences in the stimulation of specific T cell responses between these two species. Differences in immunogenicity between the different clinical isolates of $S$. schenckii sensu lato and the recognition of several fungal antigens by specific antibodies induced in infected human, cats and rodents have been reported (Fernandes et al., 2013; Della Terra et al., 2017). Moreover, some studies have addressed the role of the cellular-mediated immune response in sporotrichosis by evaluating the $\mathrm{T}$ helper immune response induced in vitro or in murine models of systemic S. schenckii sensu stricto infection (Uenotsuchi et al., 2006; Maia et al., 2006; Ferreira et al., 2015; Gonçalves et al., 2017). However, the role of Tregs in sporotrichosis has yet to be determined, and comparative studies of $\mathrm{T}$ cells response against different species of S. schenckii sensu lato have not been conducted.

The objective of this work was to comparatively analyze the virulence and the CD4+T-lymphocyte response induced by $S$. schenckii sensu stricto and $S$. brasiliensis in a murine model of subcutaneous sporotrichosis.

\section{Materials and methods}

\subsection{Microorganism and culture conditions}

S. schenckii strain 1099-18, was kindly provided by Dr. Celuta Sales Alviano at the Institute of Microbiology, Federal University of Rio de
Janeiro (Brazil). This strain was originally isolated from a human case of sporotrichosis at the Mycology Section of the Department of Dermatology, Columbia University (New York, NY, USA). S. brasiliensis ss250 (CBS 133009, GenBank: KC693883.1), was originally isolated from a feline sporotrichosis case in Brazil, and was kindly provided by Dr. Sandro Pereira at the Oswaldo Cruz Foundation, (Rio de Janeiro, Brazil). For experimental infection, the mycelia phase of each strain was grown in Sabouraud broth (Difco, Detroit, USA) for $5 \mathrm{~d}$ at $28-30{ }^{\circ} \mathrm{C}$, and the culture was filtered through sterile gauze to isolate conidia from hyphae (Castro et al., 2013).

\subsection{Experimental infection}

Male C57BL6 mice, 5-7 weeks old, were purchased from Centro Multidisciplinary para Investigacao Biologica na Area da Ciencia de Animais de Laboratorio" (CEMIB), UNICAMP University. This work was approved by the Institutional Ethics Committee for Animal Use in Research (Protocol CEUA/FCF/CAR no. 08/2016) and was in accordance with the National Institutes of Health Animal Care guidelines. Either S. schenckii sensu stricto or S. brasiliensis-infected mice and non-infected mice forming three groups were housed (Three mice/microisolator cage/group) in specific pathogen-free (SPF) conditions. Each mouse of infected groups were subcutaneously inoculated in the dorsal sacral region with $10^{7}$ conidia suspended in $200 \mu \mathrm{L}$ of sterile PBS or sterile PBS (control group) (Castro et al., 2013). Conidial viability was confirmed by colony forming unit (CFU) count of conidia suspension cultured onto Mycosel agar (BD Biosciences) plates. Infected and control mice were monitored daily for until $35 \mathrm{~d}$ to evaluate the progression of the disease. The extension of the primary skin lesion was monitored at 7, 21 and 35 d postinfection (d.p.i). Three mice of each group were euthanized in each time, and the skin lesion, liver and spleen were removed and weighted to assess the fungal load, in order to evaluate local and systemic fungal load. Three independent experiments were performed.

\subsection{Preparing tissue homogenates from mouse skin}

Skin punches measuring $6 \mathrm{~mm}$ were homogenized in $1.5 \mathrm{~mL}$ extraction buffer (containing $10 \mathrm{mM}$ Tris pH 7.4, $150 \mathrm{mM} \mathrm{NaCl}, 1 \%$ Triton X-100) per gram of tissue using a glass homogenizer. The homogenates were transferred to $1.5 \mathrm{~mL}$ Eppendorf tubes, centrifuged at $13,000 \times \mathrm{g}$ for $10 \mathrm{~min}$ at $4{ }^{\circ} \mathrm{C}$, and the supernatant was stored at $-80^{\circ} \mathrm{C}$ until analyzed (Blalock et al., 2001). TNF-alpha and IL-6 protein levels were determined as described in 2.6.

\subsection{Histopathology study}

Skin fungal inoculation site, liver and hind paws were fixed with $10 \%$ buffered formalin. Samples were dehydrated, paraffinembedded, and sectioned. Then, they were stained with haemaoxylin and eosin or Periodic Acid-Schiff (PAS) to observe the presence of the fungi in the tissue. Analysis was made by optical microscopy (NIKON Eclipse TS100, Tokyo, Japan), and photos were captured by VD480 OPTMEDICAL software.

\subsection{Th1, Th17 and Tregs analysis by flow cytometer}

Spleens were aseptically removed and splenocytes were extracted as previously described (Ferreira et al., 2015). Viable splenocytes were adjusted to $1 \times 10^{7}$ cells/mL in RPMI-1640 (Sigma-Aldrich, Germany), supplemented with $2 \mathrm{~mm}$ L-glutamine. 100 $\mathrm{U} / \mathrm{mL}$ penicillin. $100 \mu \mathrm{g} / \mathrm{mL}$ penicillin/streptomycin and $10 \%$ fetal calf serum (RPMI complete). The following anti-mouse $\mathrm{mAb}$ were used: anti-CD16/CD32, anti-CD3-FITC, anti-CD4-APC, anti-IL-17-PE; 
anti-IFNy; anti-CD25-PE; anti Foxp3-PE-Cy7 and respective isotype controls. Splenocytes were assessed for the frequency of Th1(IFNy+), Th17 (IL-17+), Th1-Th17 (IFNy+Th17+) and Tregs $(\mathrm{CD} 25+$ Foxp3+). Briefly, cells were stained for the extracellular markers, then fixed and permeabilized using eBiosciences' intracellular fixation \& permeabilization buffer set, and then stained for the transcription factors Foxp3. Intracellular IFNy and IL-17 were detected after in vitro stimulation with cell stimulation cocktail containing phorbol 12-myristate 13-acetate (PMA) and ionomycin to induce cytokine production and Brefeldin $\mathrm{A} /$ Monensin for intracellular retention of the induced cytokine expression (eBioscience). Events were acquired using a BD Accuri C6 flow cytometer (BD Biosciences) and analyzed within the flow cytometer's proprietary software.

\subsection{Cytokines in serum and skin}

Seven cytokines were measured in the local site of infection on $24 \mathrm{~h}$ post-infection and in sera at 7th, 21st and 35th d.p.i in uninfected and infected mice by Cytometric Bead Array (CBA) with BD CBA Mouse Th1/Th2/Th17 Cytokine Kit (BD Bioscience, Catalog No. 560485). Briefly, The BD CBA Mouse Th1/Th2/Th17 Cytokine Kit uses bead array technology to simultaneously detect multiple cytokine proteins in biological samples. The kit was used for the simultaneous detection of mouse interleukin-2 (IL-2), interleukin-4 (IL-4), interleukin-6 (IL-6), interferon- $\gamma$ (IFN- $\gamma$ ), tumor necrosis factor (TNFalpha), interleukin-17A (IL-17A), and interleukin-10 (IL-10) in a single sample. Each bead carrying an specific anti-cytokine capture antibody emits different fluorescence intensities. The seven bead populations are mixed together to form the bead array, which is resolved in a red channel (ie, FL3) of the cytometer. After that, similar volume $(50 \mu \mathrm{l})$ of pooled beads, biological sample and Th1/Th2/Th17 PE Detection antibody are mixed, incubated $2 \mathrm{~h}$, washed and analyzed with a BDAccuri C6 flow cytometer (BD Biosciences, CA). Cytokine concentrations were extrapolated from a standard curve that was run in parallel and the value were expressed in $(\mathrm{pg} / \mathrm{mL})$.

\subsection{Statistical analysis}

Statistical analysis was performed in GraphPad Prism ver. 6.01. The results are expressed as the mean \pm SD and the statistical significance was analyzed using one or two-way analysis of variance (ANOVA) with Tukey or Sidak's multiple comparisons test, respectively. Student's t-test was also used where indicated. In this study, a $\mathrm{p}$ value of $<0.05$ was considered significant.

\section{Results}

\subsection{Progression of subcutaneous infection and systemic dissemination}

The progression of infection was determined weekly by assessing the diameter of the primary lesion on the skin and in subcutaneous tissue. Furthermore, systemic dissemination (fungal burden in the spleen and liver) was evaluated by CFU counts. Locally, there were not significant differences in CFU counts between S. schenckii and S. brasiliensis throughout the study (Fig. 1A); however, $S$. brasiliensis-infected mice developed more extensive and long lasting local lesion (Fig. 1B). S. brasiliensis was also more efficient in colonizing distant sites than $S$. schenckii sensu stricto. $S$. schenckii CFU counts in the spleen and liver decreased rapidly after the 7th week, while $S$. brasiliensis maintained a higher organ burden throughout the experiment (Fig. 1C,D). At 35 d.p.i. severe fungal infiltration, inflammation and increased spleen weight were observed in the S. brasiliensis-infected mice. Several animals of both infected groups also developed orchitis and nodular lesions in the tail. These and others clinical manifestations were depicted in Table 1 and Supplementary figures (S1 and S2).

\subsection{Histological assessment}

To confirm the above results, the local inoculation site and the liver were studied histopathologically. Fungal cells were defined by the presence of yeast-like structures that were consistent with round, oval or cigar-shaped yeasts, with $2-6 \mu \mathrm{m}$ of diameters and exhibited positive staining for PAS. As observed in Fig. 2, all cases were characterized by suppurative granulomatous processes with different grades of development on the skin. Relative to S. schenckii sensu stricto infection, mice infected with $S$. brasiliensis developed more extensive areas containing well-formed granulomas that were associated with greater fungal and inflammatory cells infiltration, which predominantly included epithelioid cells, lymphocytes and neutrophils.

In the liver, disseminated white to yellowish-white nodules were observed in mice infected with $S$. brasiliensis. In animals infected with $S$. schenckii sensu stricto, nodules were either not observed or very scarcely present, which was the case in a small number of animals. Microscopically, it was observed well-formed tuberculoid granulomas were observed with central caseous necrosis, Langhans giant cells and surrounding lymphoplasmacytic infiltrate, associated to neutrophils and eosinophils. In contrast, $S$. schenckii-infected mice developed small granulomes with few presences of fungi and less extensive inflammatory cells (Fig. 3).

\subsection{Th1, Th17 and Tregs analysis}

The Fig. 4 shows the percentage values of Th1, Th17 and Tregs in the spleen at 7, 21 and 35 d.p.i. Both groups of infected mice, exhibited a higher level of Th responses at 21 d.p.i, but different responses were observed between the groups at 35 d.p.i. Mice infected with S. schenckii sensu stricto showed a decreased in Th1/Th7 and Tregs responses while those mice infected with $S$. brasiliensis maintained an elevated Tregs response associated to a dramatic Th17 + Th1- response.

\subsection{Cytokines levels in serum and the skin}

With the aim of evaluating the impact of the infection in the pattern of cytokines on the skin during the first $24 \mathrm{~h}$, the profile of TNF-alpha, IL-6 and IL-10 were studied at the inoculation site. Mice infected with S. schenckii sensu stricto, produced elevated levels of TNF-alpha and IL-6, relate to those infected with S. brasiliensis. IL-10 production was not modified in any group (Fig. 5).

Differential expression of circulating cytokines in the serum was also observed on the 7th, 21st and 35th d.p.i between the experimental groups (Fig. 6). In contrast to what occured at the inoculation site during the beginning stages of infection, S. brasiliensis induced increased production of all measured cytokines, compared with S. schenckii sensu stricto except IL-17A and IL-10 whose values were only higher 35 d.p.i. At that time, the group infected with Sporothrix brasiliensis maintained high levels of all measured cytokines, with the exception of IFNy, which showed a tendency to decrease from 7 to 35 d.p.i (Fig. 6).

\section{Discussion}

The T cell-mediated immune response is essential for the control of fungal infections (van de Veerdonk and Netea, 2010; Roussey et al., 2016). The role of Th cells in sporotrichosis has been studied in models of Sporothrix shenckii sensu strictu infection. However, 
A
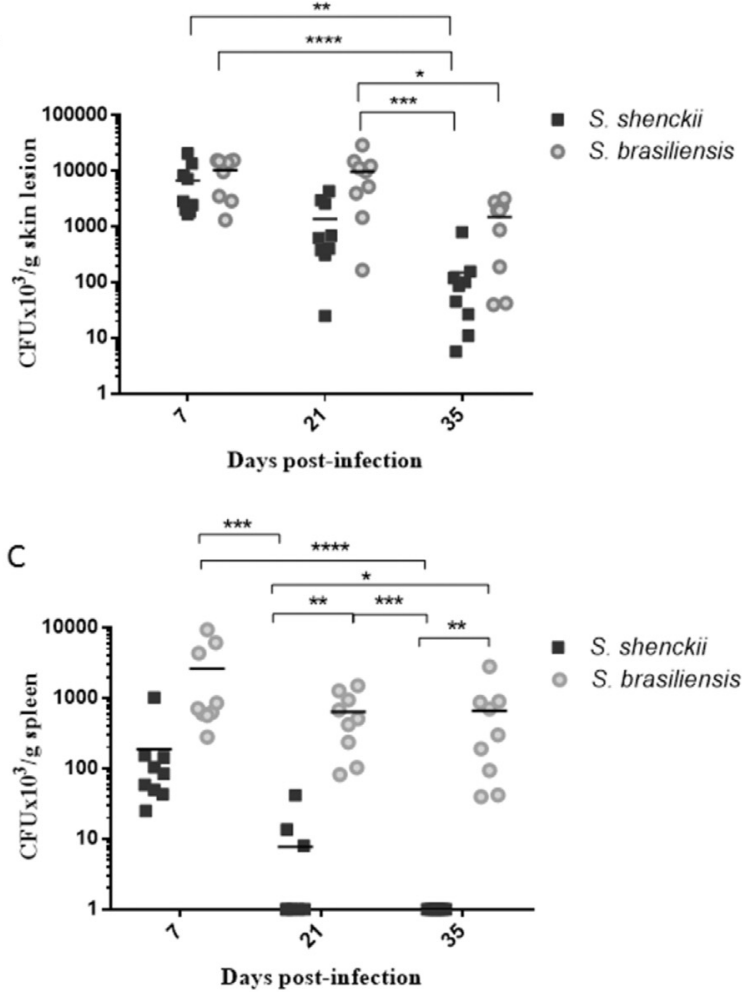

B

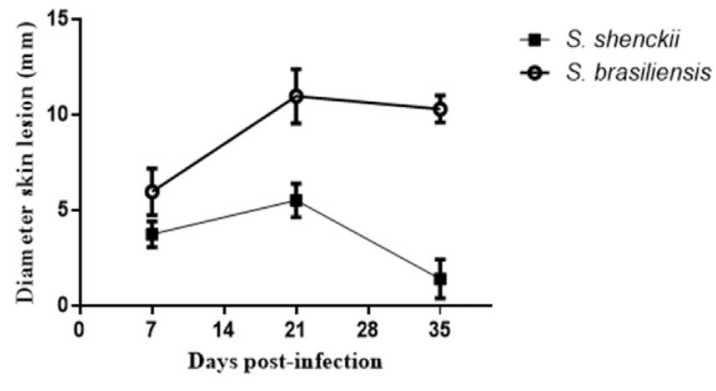

D

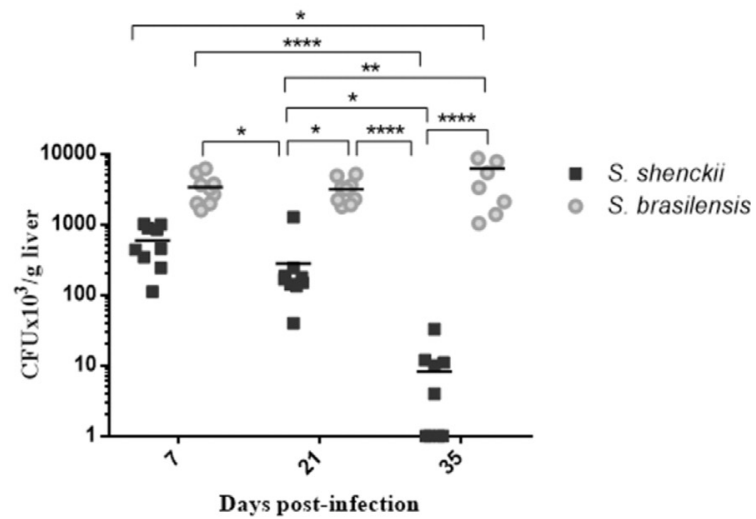

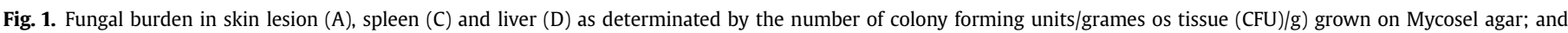

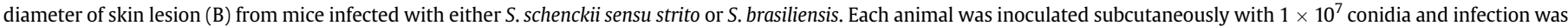

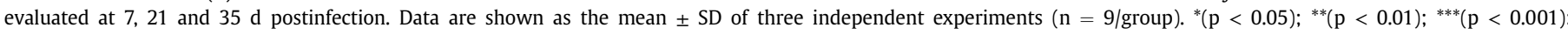
${ }^{* * * *}(\mathrm{p}<0.0001)$ as determined by the number of colony-forming units grown on Mycosel agar.

Table 1

Evaluation of the progression of sporotrichosis caused by S. schenckii sensu stricto and S. brasiliensis in a subcutaneous murine model at $35 \mathrm{~d}$ postinfection.

\begin{tabular}{ll}
\hline Clinical findings & S. schenckii sensu stricto \\
\hline Ulcerated open lesion in the fungal inoculation site (skin) & $5 / 9$ \\
Secondary nodular lesions along the tail & $4 / 9$ \\
Inflammation in the paw and posterior leg joints (arthritis) & $9 / 9$ \\
Orchitis & $3 / 9$ \\
Macroscopic lesions in the liver & $4 / 9$ \\
Splenomegaly & $3 / 9$ \\
Death & $9 / 9$ \\
\hline
\end{tabular}

a Representative imagens are showed in Fig. S2.

b A kinetic of spleen weight on days 7, 21 and 35 d postinfection is showed in Fig. S1.

there is little information on the different $\mathrm{T}$ cell response patterns induced by the different pathogenic species of S. schenckii sensu lato. To attempt to answer this question, at least in part, the differences in T helper cells and Tregs induced by S. schenckii sensu stricto and $S$. brasiliensis infections were shown for the first time in a model of subcutaneous infection, as this is the usual way of entry for the fungi (Castro et al., 2013).

In this model, S. schenckii infection was rapidly controlled with a sustained reduction of the local and systemic fungal load. Interestingly, S. schenckii sensu stricto stimulated a high production of the proinflammatory cytokines TNF-alpha and IL-6 at the site of infection on $24 \mathrm{~h}$ after inoculation, while the concentration of these cytokines in mice infected with $S$. brasiliensis remained similar to that of uninfected mice. A similar pattern was reported by Martínez-Álvarez et al. (2017). These authors compared the ability of $S$. brasiliensis and S. schenckii sensu stricto cells to stimulate cytokine production in human peripheral blood mononuclear cells and observed that conidia and yeast of S. schenckii sensu stricto induced increased levels of proinflammatory cytokines, when compared to $S$. brasiliensis cells. The poor stimulation of the innate immune system by $S$. brasiliensis during early stages of infection can be explained, at least in part, by differences in the cell wall composition (Martínez-Álvarez et al., 2017; Lopes-Bezerra et al. 2018) and differentially expressed proteins that are potentially involved in immune evasion between these two species (Rossato et al., 2018). These differences can impact the infiltration and activation of macrophages and possibly dendritic cells, favoring the higher and longer lasting systemic dissemination of $S$. brasiliensis when compared with S. schenckii sensu stricto.

A previous report by our group in a model of S. schenckii sensu strito systemic infection (Gonçalves et al., 2017) showed that the highest response of Th1, Th17 and Tregs cells were observed approximately $21 \mathrm{~d}$.p.i, and were reduced as the clearance of fungi occurred. A similar pattern was observed in the current model of subcutaneous infection. However, in this study, we observed that the immune response induced by $S$. brasiliensis was less effective in 

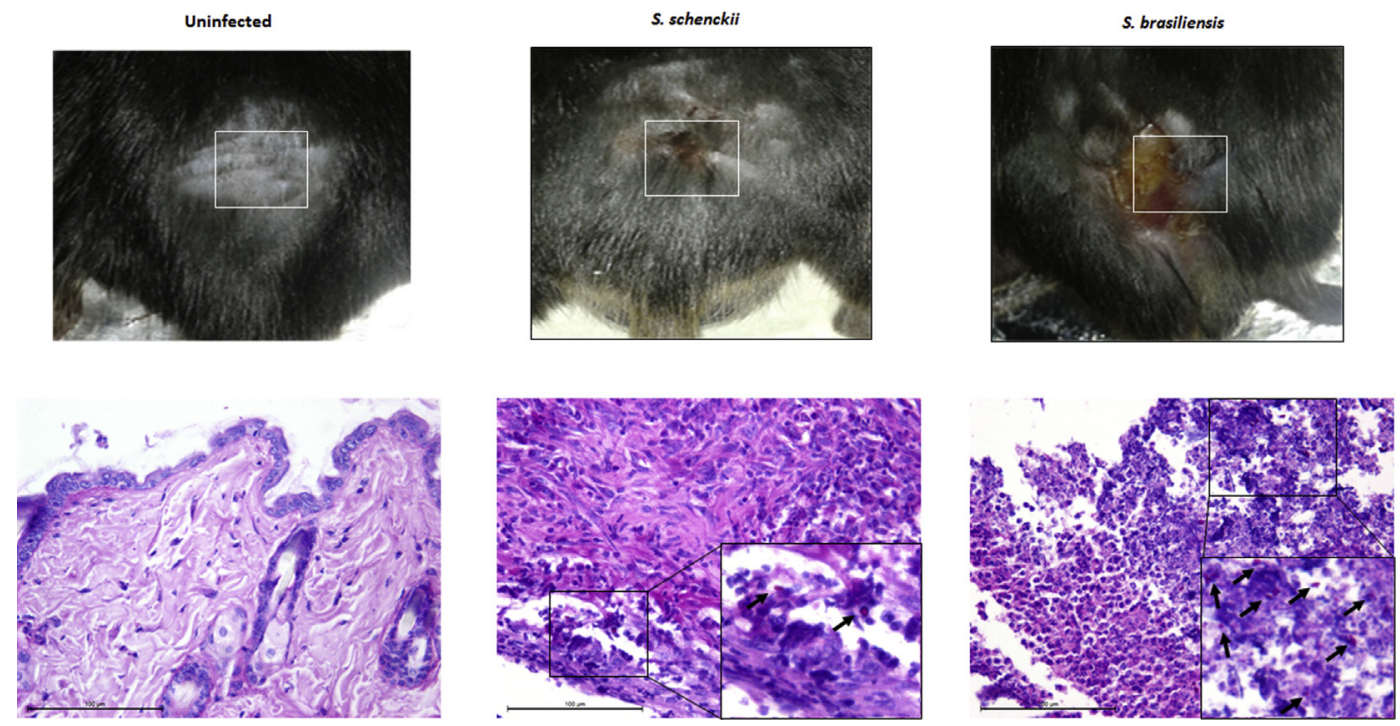

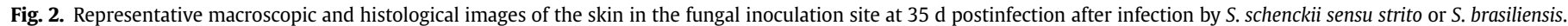
The control group was inoculated with vehicle (PBS). Original magnification $10 \times$, and $400 \times$. Periodic Acid Schiff Stain.
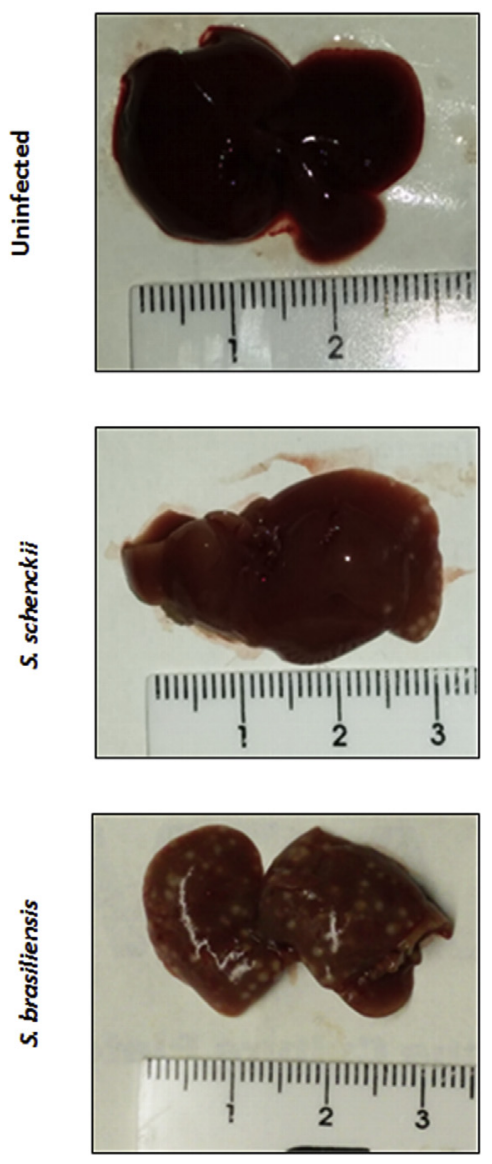
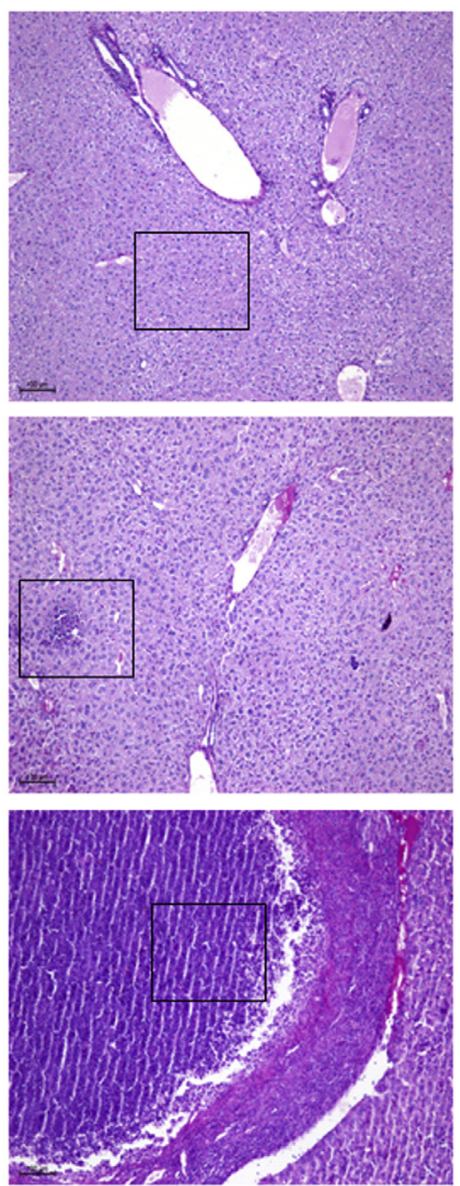
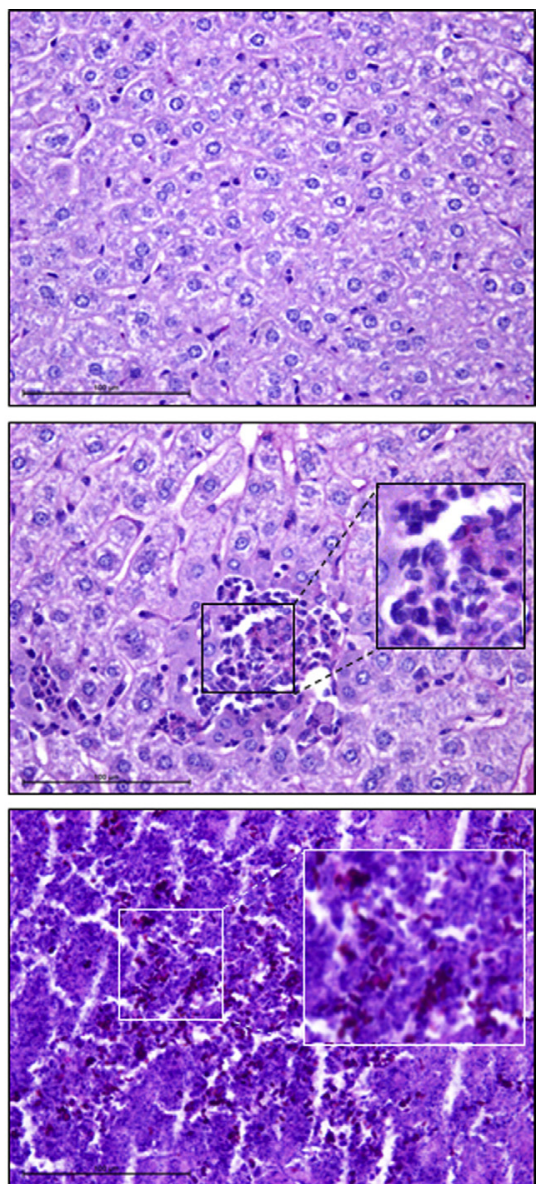

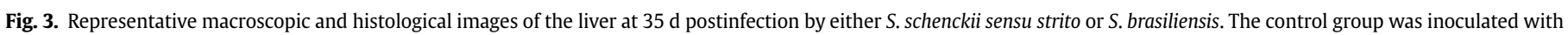
vehicle (PBS). Original magnification $10 \times$, and $400 \times$. Periodic Acid Schiff Stain.

controlling the infection, as evidenced by the high fungal load throughout the study.

The presence of large hepatic granulomas disseminated throughout the liver loaded with numerous oval and cigar-shaped
PAS-positive yeast in S. brasiliensis-infected mice was notable. A similar finding was reported by Arrillaga-Moncrieff et al. (2009), after intravenous infection of highly virulent isolates of $S$. schenckii sensu stricto. 
Th1

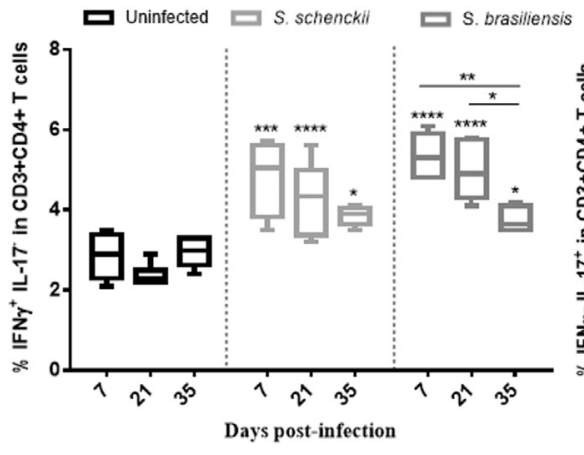

Tregs

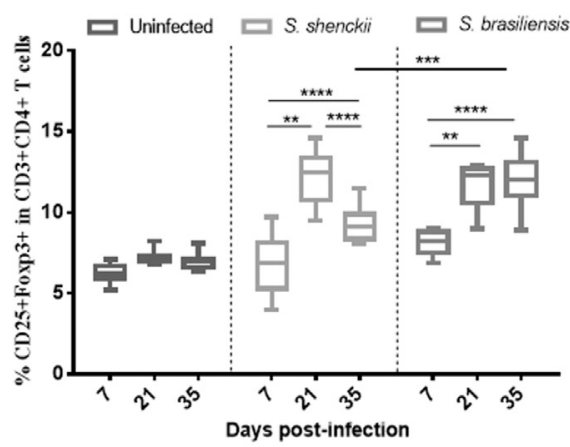

Th17

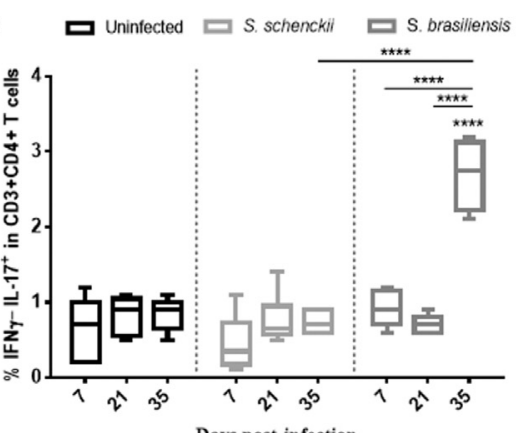

Th1-Th17

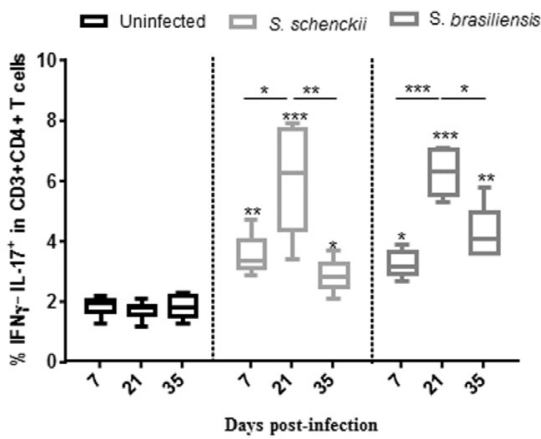

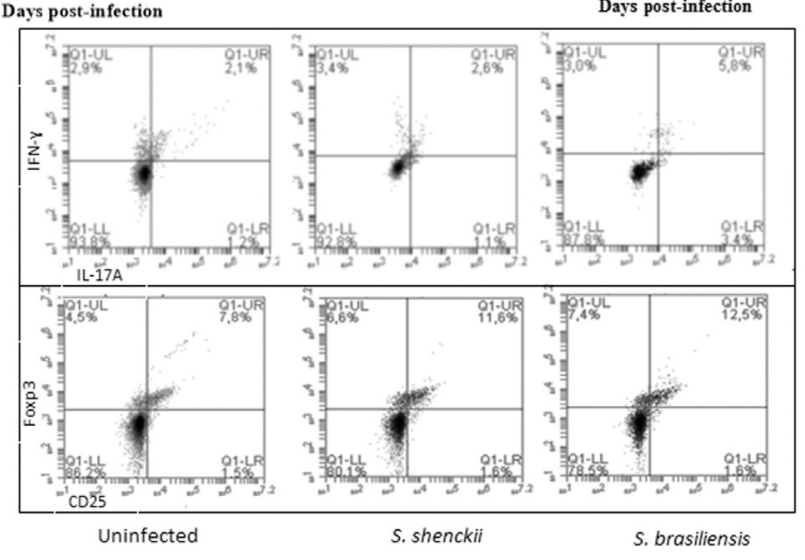

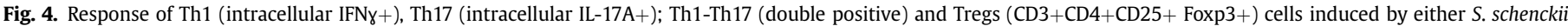

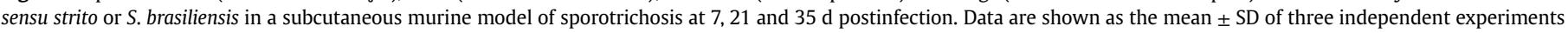
$(\mathrm{n}=9 /$ group $) *(\mathrm{p}<0.05) ;{ }^{* *}(\mathrm{p}<0.01) ;{ }^{* * *}(\mathrm{p}<0.001):{ }^{* * * *}(\mathrm{p}<0.0001)$.

IL-6

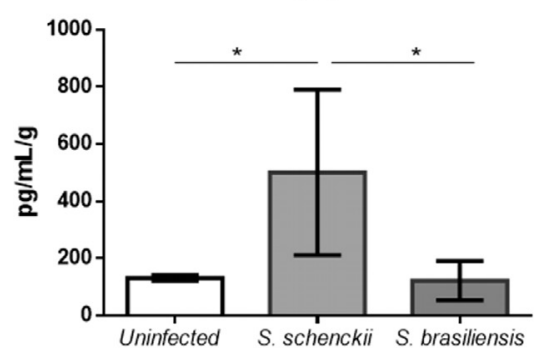

TNF-alpha

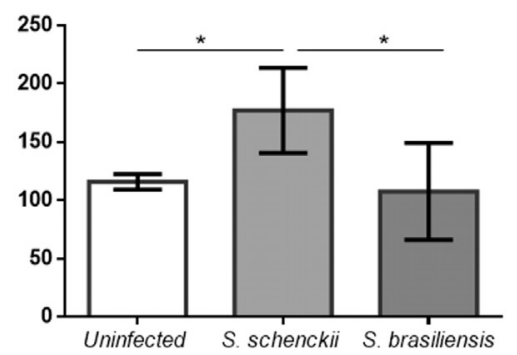

IL-10

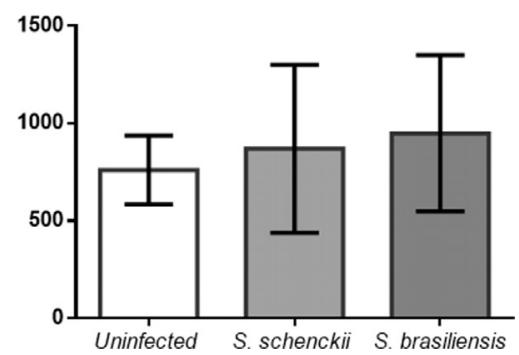

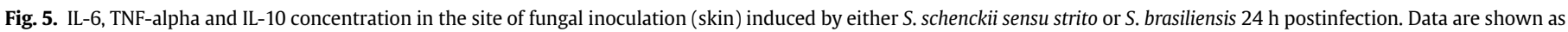
the mean \pm SD of three independent experiments and are expressed in $\mathrm{pg} / \mathrm{mL} / \mathrm{g}$ of skin $(\mathrm{n}=9 / \mathrm{group}) .{ }^{*}(\mathrm{p}<0.05)$.

Once again, the role of Th1 and Th17 lymphocytes in the immune response against this fungus was demonstrated. Th1 and double positive Th1-Th17 (IFNy+IL-17A+) cells were stimulated by the two species. The inflammatory infiltrate at the sites of infection excibited large numbers of monocytes and neutrophils, suggesting cooperative Th1 and Th17 activity for fungal clearance (van de Veerdonk and Netea, 2010). However, at 35 d.p.i a different characteristic in the Th1 and Th17 profile was observed. While a reduction in Th1 and Th1-Th17 responses was observed upon $S$. schenckii clearance, a similar reduction, in the observed Th1 response to $S$. brasiliensis infection at 35 d.p.i seems to have been caused by the immunosuppressive effect of the Tregs that were exacerbated at that time. Interestingly, a sudden and dramatic Th17 response was observed in this group.

Regulation of the antifungal T-helper response is crucial for the resolution of the inflammatory response after fungal clearance to prevent detrimental immunopathology (Kroetz and Deepe, 2010;
Dewi et al., 2017). The high levels of Tregs observed on day 35 post-S. brasiliensis infection suggest an immunosuppressive response to counteract the excessive multi-organs inflammation. It seems that the increase in Tregs leds to inhibitory effect on Th1 cells and a strong stimulation of Th17 cells as a possible compensatory antifungal mechanisms.

The role of Tregs in fungal infection is still controversial. Some studies showed that Tregs increased protective immunity (Pandiyan et al., 2011, Netea et al., 2004, Schulze et al., 2014, Wiesner et al., 2016), while in other models, Tregs promoted fungal infection (Felonato et al., 2012; Whibley et al., 2014). Our results suggest that, in addition to the immunosuppressive role of Tregs in avoiding excessive inflammation, they may also favor a shift to a Th17 response, promoting the elimination of the pathogen in advanced stages of infection (Kanashiro-Galo et al., 2016; Sehrawat and Rouse, 2017). The effect of Tregs on the Th17 function in fungal infection is also controversial. Osorio et al. (2008), 

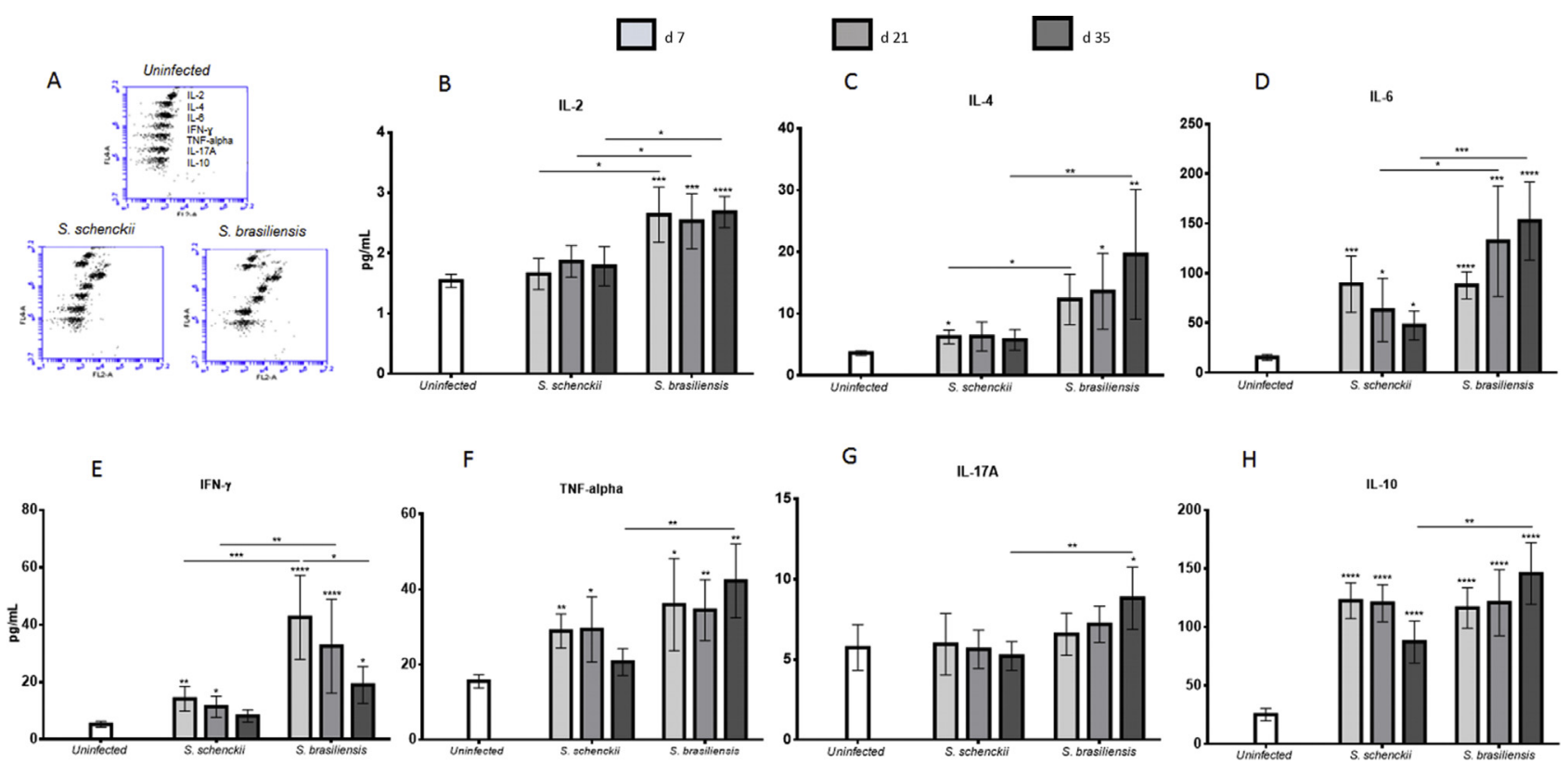

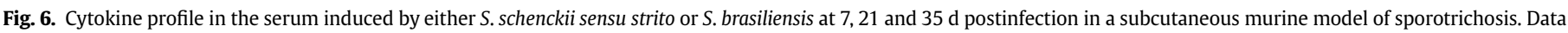
are shown as the mean \pm SD of three independent experiments. $\left(\mathrm{n}=9\right.$ /group). ${ }^{*}(\mathrm{p}<0.05) ;{ }^{* *}(\mathrm{p}<0.01){ }^{* * *}(\mathrm{p}<0.001) ;{ }^{* * * *}(\mathrm{p}<0.0001)$.

reported that the stimulation of bone marrow-derived dendritic cells with curdlan triggered the conversion of Foxp3+IL-17- cells into IL-17-expressing Foxp3+ cells, suggesting that dectin-1 enhances the Th17 response by Tregs plasticity. Thus, the role of dectin-1 in anti-sporothrix defense have been recently reported (Jellmayer et al., 2017; Martínez-Álvarez et al., 2017). Moreover, studies performed in murine models of $C$. albicans infection have showed that Tregs are markedly increased in infected mice compared to uninfected control mice. These Tregs inhibited Th1 and Th2 activity but promoted a Th17 response (Pandiyan et al., 2011; Whibley et al., 2014). Owing to the inhibition of Th17 development by IL-2, the enhancement of Th17 cell abundance was, in part, attributable to the Tregs preferential consumption of IL-2 (Pandiyan et al., 2011; Whibley et al., 2014). Tregs can differentiate into Th17 cells in the presence of IL- 6 (and in the absence of exogenous TGF- $\beta$ ) and induce naive CD4+CD25-T-cell differentiation into IL-17-producing cells, (Kitani and Xu, 2008; BatistaDuharte et al., 2018b). In contrast, other studies using the same infectious agent, $C$. albicans, have suggested an inhibitory effect of Tregs on Th17 activity (De Luca et al., 2007). Given these findings, new studies are being carried out by our group using Tregs depletion models to define the impact of these cells on other $\mathrm{T}$ populations for the control of the infection and the inflammatory response induced by these two species. The understanding of these mechanisms will have an undeniable impact on the design of immunomodulatory drugs and vaccines for the control of sporotrichosis, wich represent a growing area of research that promises important advances in the immediate future (Batista-Duharte et al., 2016; Almeida et al., 2015; Portuondo et al., 2016, 2017; de Almeida et al., 2018).

\section{Conclusions}

The present results reinforce the need for comparative studies of virulence associated with immunomodulation induced by pathogenic species of $S$. schenckii sensu lato. In this study, important differences between Th and Tregs response to the most virulent species of $S$. schenckii sensu lato were shown for the first time.
Infection with S. schenckii sensu lato was controlled with Th1 and Th1-Th17 response, associated to a late Tregs to maintain the tissue homeostasis. Furthermore, S. brasiliensis caused a more disseminated and lasting infection as well as greater tissue damage in a model of subcutaneous infection. The higher virulence of S. brasiliensis was associated with poor stimulation of the innate immune system in the skin and subcutaneous tissue and a reduction of the Th1 response with higher Th17 and Tregs profile in the advanced phase of infection. This pattern in S. brasiliensis infection suggests a $\mathrm{T}$ cell bias that favors a Th17-mediated immune response in an attempt to control the severe fungal infection while reducing the excessive and deleterious inflammatory response by means of Tregs activity. Future studies are needed to unravel the mechanisms behind the differential response profiles induced by these two species and to determine the beneficial or detrimental effect of Tregs during chronic stages of infection.

\section{Conflicts of interest}

The authors declare no commercial or financial conflict of interest.

\section{Acknowledgments and funding}

This work was supported by Fundacão de Amparo à Pesquisa do Estado de São Paulo (FAPESP), grant $N \circ 2016 / 04250-0$.

\section{Appendix A. Supplementary data}

Supplementary data to this article can be found online at https://doi.org/10.1016/j.funbio.2018.08.004.

\section{References}

Almeida, J.R., Kaihami, G.H., Jannuzzi, G.P., de Almeida, S.R., 2015. Therapeutic vaccine using a monoclonal antibody against a 70-kDa glycoprotein in mice infected with highly virulent Sporothrix schenckii and Sporothrix brasiliensis. Med. Mycol. 53, 42-50. 
Arrillaga-Moncrieff, I., Capilla, J., Mayayo, E., Marimon, R., Mariné, M., Gené, J., Cano, J., Guarro, J., 2009. Different virulence levels of the species of Sporothrix in a murine model. Clin. Microbiol. Infect. 15 (7), 651-655.

Batista-Duharte, A., Martínez, D.T., da Graça Sgarbi, D.B., Carlos, I.Z., 2015. Environmental conditions and fungal pathogenicity. In: Carlos, I.Z. (Ed.), Sporotrichosis: New Developments and Future Prospects, first ed. Springer, Switzerland, pp. $53-72$.

Batista-Duharte, A., Lastre, M., Romeu, B., Portuondo, D.L., Téllez-Martínez, D., Manente, F.A., Pérez, O., Carlos, I.Z., 2016. Antifungal and immunomodulatory activity of a novel cochleate for amphotericin B delivery against Sporothrix schenckii. Int. Immunopharm. 40, 277-287.

Batista-Duharte, A., Téllez-Martínez, D., Aparecida Jellmayer, J., Leandro Portuondo Fuentes, D., Campos Polesi, M., Martins Baviera, A., Zeppone Carlos, I., 2018a. Repeated exposition to mercury (II) chloride enhances susceptibility to S. schenckii sensu stricto infection in mice. J. Fungi (Basel) 4 (2), E64.

Batista-Duharte, A., Téllez-Martínez, D., Fuentes, D.L.P., Carlos, I.Z., 2018b. Molecular adjuvants that modulate regulatory $\mathrm{T}$ cell function in vaccination: a critical appraisal. Pharmacol. Res. 129, 237-250.

Beurmann, L., Gougerot, H., 1912. Les Sporotrichoses. Félix Alcan edit, París.

Blalock, T.D., Varela, J.C., Gowda, S., Tang, Y., Chen, C., Mast, B.A., Schultz, G.S., 2001 Ischemic skin wound healing models in rats. Wounds A Comp. Clin. Res. Pract. 13 (1), 35-44.

Bonifaz, A., Tirado-Sánchez, A., 2017. Cutaneous disseminated and extracutaneous sporotrichosis: current status of a complex disease. J. Fungi (Basel) 3 (1), E6.

Carlos, I.Z., Batista-Duharte, A., 2015. Sporotrichosis: an emergent disease. In: Carlos, I.Z. (Ed.), Sporotrichosis: New Developments and Future Prospects, first ed. Springer, Switzerland, pp. 1-23.

Carlos, I.Z., Zini, M.M., Sgarbi, D.B., Angluster, J., Alviano, C.S., Silva, C.L., 1994. Disturbances in the production of interleukin-1 and tumor necrosis factor in disseminated murine sporotrichosis. Mycopathologia 127 (3), 189-194.

Castro, R.A., Kubitschek-Barreira, P.H., Teixeira, P.A., Sanches, G.F., Teixeira, M.M., Quintella, L.P., Almeida, S.R., Costa, R.O., Camargo, Z.P., Felipe, M.S., de Souza, W., Lopes-Bezerra, L.M., 2013. Differences in cell morphometry, cell wall topography and gp70 expression correlate with the virulence of Sporothrix brasiliensis clinical isolates. PLoS One 8 (10), e75656.

Chakrabarti, A., Bonifaz, A., Gutierrez-Galhardo, M.C., Mochizuki, T., Li, S., 2015. Global epidemiology of sporotrichosis. Med. Mycol. 53 (1), 3-14.

de Almeida, J.R.F., Jannuzzi, G.P., Kaihami, G.H., Breda, L.C.D., Ferreira, K.S., de Almeida, S.R., 2018. An immunoproteomic approach revealing peptides from Sporothrix brasiliensis that induce a cellular immune response in subcutaneous sporotrichosis. Sci. Rep. 8 (1), 4192.

de Beer, Z.W., Duong, T.A., Wingfield, M.J., 2016. The divorce of Sporothrix and Ophiostoma: solution to a problematic relationship. Stud. Mycol. 83, 165-191.

Della Terra, P.P., Rodrigues, A.M., Fernandes, G.F., Nishikaku, A.S., Burger, E., de Camargo, Z.P., 2017. Exploring virulence and immunogenicity in the emerging pathogen Sporothrix brasiliensis. PLoS Neglected Trop. Dis. 11 (8) e0005903.

De Luca, A., Montagnol, i C., Zelante, T., Bonifazi, P., Bozza, S., Moretti, S. D'Angelo, C., Vacca, C., Boon, L., Bistoni, F., Puccetti, P., Fallarino, F., Romani, L., 2007. Functional yet balanced reactivity to Candida albicans requires TRIF, MyD88, and Ido-dependent inhibition of Rorc. J. Immunol. 179 (9) 5999-6008.

Dewi, I.M.W., van de Veerdonk, F.L., Gresnigt, M.S., 2017. The multifaceted role of Thelper responses in host defense against Aspergillus fumigatus. J. Fungi (Basel) 3 (4), E55.

Felonato, M., Pina, A., de Araujo, E.F., Loures, F.V., Bazan, S.B., Feriotti, C., Calich, V.L., 2012. Anti-CD25 treatment depletes Treg cells and decreases disease severity in susceptible and resistant mice infected with Paracoccidioides brasiliensis. PLoS One 7 (11), e51071.

Fernandes, G.F., dos Santos, P.O., Rodrigues, A.M., Sasaki, A.A., Burger, E., de Camargo, Z.P., 2013. Characterization of virulence profile, protein secretion and immunogenicity of different Sporothrix schenckii sensu stricto isolates compared with S. globosa and S. brasiliensis species. Virulence 4 (3), 241-249.

Ferreira, L.S., Gonçalves, A.C., Portuondo, D.L., Maia, D.C., Placeres, M.C., BatistaDuharte, A., Carlos, I.Z., 2015. Optimal clearance of Sporothrix schenckii requires an intact Th17 response in a mouse model of systemic infection. Immunobiology 220 (8), 985-992.

Gonçalves, A.C., Maia, D.C., Ferreira, L.S., Monnazzi, L.G., Alegranci, P., Placeres, M.C., Batista-Duharte, A., Carlos, I.Z., 2015. Involvement of major components from Sporothrix schenckii cell wall in the caspase-1 activation, nitric oxide and cytokines production during experimental sporotrichosis. Mycopathologia 179 (1-2), 21-30. https://doi.org/10.1007/s11046-014-9810-0.

Gonçalves, A.C., Ferreira, L.S., Manente, F.A., de Faria, C.M.Q.G., Polesi, M.C., de Andrade, C.R., Zamboni, D.S., Carlos, I.Z., 2017. The NLRP3 inflammasome contributes to host protection during Sporothrix schenckii infection. Immunology 151 (2), 154-166.

Jellmayer, J.A., Ferreira, L.S., Manente, F.A., Gonçalves, A.C., Polesi, M.C., BatistaDuharte, A., Carlos, I.Z., 2017. Dectin-1 expression by macrophages and related antifungal mechanisms in a murine model of Sporothrix schenckii sensu stricto systemic infection. Microb. Pathog. 110, 78-84.

Kanashiro-Galo, L., Pagliari, C., Barboza, T.C., de Brito, A.C., Xavier, M.B., de Oliveira, C.M., Unger, D.A., Sotto, M.N., Quaresma, J.A., Duarte, M.I., 2016. Th17 and regulatory $\mathrm{T}$ cells contribute to the in situ immune response in skin lesions of Jorge Lobo's disease. Med. Mycol. 54 (1), 23-28.
Kitani, A., Xu, L., 2008. Regulatory T cells and the induction of IL-17. Mucosal Immunol. (Suppl. 1), S43-S46.

Kroetz, D.N., Deepe Jr., G.S., 2010. CCR5 dictates the equilibrium of proinflammatory IL-17+ and regulatory Foxp3+ T cells in fungal infection. J. Immunol. 184, $5224-5231$.

Lopes-Bezerra, L.M., Walker, L.A., Niño-Vega, G., Mora-Montes, H.M., Neves, G.W.P., Villalobos-Duno, H., Barreto, L., Garcia, K., Franco, B., Martínez-Álvarez, J.A. Munro, C.A., Gow, N.A.R., 2018. Cell walls of the dimorphic fungal pathogens Sporothrix schenckii and Sporothrix brasiliensis exhibit bil aminate structures and sloughing of extensive and intact layers. PLoS Neglected Trop. Dis. 12 (3) e0006169.

Maia, D.C.G., Sassá, M.F., Placeres, M.C.P., Carlos, I.Z., 2006. Influence of Th1/Th2 cytokines and nitric oxide in murine systemic infection induced by Sporothrix schenckii. Mycopathologia 161, 11-19.

Maia, D.C., Gonçalves, A.C., Ferreira, L.S., Manente, F.A., Portuondo, D.L., Vellosa, J.C. Polesi, M.C., Batista-Duharte, A., Carlos, I.Z., 2016. Response of cytokines and hydrogen peroxide to sporothrix schenckii exoantigen in systemic experimental infection. Mycopathologia 181 (3-4), 207-215.

Manente, F.A., Quinello, C., Ferreira, L.S., de Andrade, C.R., Jellmayer, J.A. Portuondo, D.L., Batista-Duharte, A., Carlos, I.Z., 2018. Experimental sporotrichosis in a cyclophosphamide-induced immunosuppressed mice model. Med. Mycol. 56 (6), 711-722.

Mario, D.N., Schaffer, L.F., Peroza, L.R., Jesus, F.P.K., Denardi, L.B., Fachinetto, R, Alves, S.H., 2017. Sporothrix brasiliensis produces the highest levels of oxidative stress in a murine model among the species of the Sporothrix schenckii complex. Rev. Soc. Bras. Med. Trop. 50 (4), 554-557.

Martínez-Álvarez, J.A., Pérez-García, L.A., Mellado-Mojica, E., López, M.G., MartínezDuncker, I., Lópes-Bezerra, L.M., Mora-Montes, H.M., 2017. Sporothrix schenckii sensu stricto and Sporothrix brasiliensis are differentially recognized by human peripheral blood mononuclear cells. Front. Microbiol. 8, 843.

Moreira, J.A., Freitas, D.F., Lamas, C.C., 2015. The impact of sporotrichosis in HIVinfected patients: a systematic review. Infection 43 (3), 267-276.

Netea, M.G., Sutmuller, R., Hermann, C., van der Graaf, C.A., van der Meer, J.W., van Krieken, J.H., Hartung, T., Adema, G., Kullberg, B.J., 2004. Toll-like receptor 2 suppresses immunity against Candida albicans through induction of IL-10 and regulatory T cells. J. Immunol. 172, 3712-3718.

Osorio, F., LeibundGut-Landmann, S., Lochner, M., Lahl, K., Sparwasser, T., Eberl, G., Reis e Sousa, C., 2008. DC activated via dectin-1 convert Treg into IL-17 producers. Eur. J. Immunol. 38 (12), 3274-3281.

Pandiyan, P., Conti, H.R., Zheng, L., Peterson, A.C., Mathern, D.R., HernándezSantos, N., Edgerton, M., Gaffen, S.L., Lenardo, M.J., 2011. CD4 $(+)$ CD25(+) Foxp3(+) regulatory $\mathrm{T}$ cells promote Th17 cells in vitro and enhance host resistance in mouse Candida albicans Th17 cell infection model. Immunity 34 (3), 422-434.

Portuondo, D.L., Batista-Duharte, A., Ferreira, L.S., Martínez, D.T., Polesi, M.C. Duarte, R.A., de Paula E Silva, A.C., Marcos, C.M., Almeida, A.M., Carlos, I.Z., 2016. A cell wall protein based vaccine candidate induce protective immune response against Sporothrix schenckii infection. Immunobiology 221, 300-309.

Portuondo, D.L., Batista-Duharte, A., Ferreira, L.S., de Andrade, C.R., Quinello, C., Téllez-Martínez, D., de Aguiar Loesch, M.L., Carlos, I.Z., 2017. Comparative efficacy and toxicity of two vaccine candidates against Sporothrix schenckii using either Montanide ${ }^{\mathrm{TM}}$ Pet Gel A or aluminum hydroxide adjuvants in mice. Vaccine 35, 4430-4436.

Rossato, L., Moreno, L.F., Jamalian, A., Stielow, B., de Almeida, S.R., de Hoog, S., Freeke, J., 2018. Proteins potentially involved in immune evasion strategies in sporothrix brasiliensis elucidated by ultra-high-resolution mass spectrometry. mSphere 3 (3), e00514-e00517.

Roussey, J.A., Olszewski, M.A., Osterholzer, J.J., 2016. Immunoregulation in fungal diseases. Microorganisms 4 (4), E47.

Sehrawat, S., Rouse, B.T., 2017. Interplay of regulatory T cell and Th17 cells during infectious diseases in humans and animals. Front. Immunol. 8, 341.

Schulze, B., Piehler, D., Eschke, M., von Buttlar, H., Köhler, G., Sparwasser, T., Alber, G., 2014. CD4(+) FoxP3(+) regulatory T cells suppress fatal T helper 2 cell immunity during pulmonary fungal infection. Eur. J. Immunol. 44 (12) 3596-3604.

Téllez, M.D., Batista-Duharte, A., Portuondo, D., Quinello, C., Bonne-Hernández, R. Carlos, I.Z., 2014. Sporothrix schenckii complex biology: environment and fungal pathogenicity. Microbiology 160 (Pt 11), 2352-2365.

Uenotsuchi, T., Takeuchi, S., Matsuda, T., Urabe, K., Koga, T., Uchi, H., Nakahara, T., Fukagawa, S. Kawasaki, M., Kajiwara, H., Yoshida, S., Moroi, Y. Furue, M. 2006. Differential induction of Th1-prone immunity by human dendritic cells activated with Sporothrix schenckii of cutaneous and visceral origins to determine their different virulence. Int. Immunol. 18 (12), 1637-1646.

van de Veerdonk, F.L., Netea, M.G., 2010. T-cell subsets and antifungal host defenses. Curr. Fungal Infect. Rep. 4 (4), 238-243.

Whibley, N., Maccallum, D.M., Vickers, M.A., Zafreen, S., Waldmann, H., Hori, S. Gaffen, S.L., Gow, N.A., Barker, R.N., Hall, A.M., 2014. Expansion of Foxp3(+) Tcell populations by Candida albicans enhances both Th17-cell responses and fungal dissemination after intravenous challenge. Eur. J. Immunol. 44 (4) 1069-1083.

Wiesner, D.L., Smith, K.D., Kotov, D.I., Nielsen, J.N., Bohjanen, P.R., Nielsen, K., 2016 Regulatory $\mathrm{T}$ cell induction and retention in the lungs drives suppression of detrimental Type 2 Th cells during pulmonary Cryptococcal infection. J. Immunol. 196 (1), 365-374. 